\title{
A AVALIAÇ̃̃O DE POLÍTICAS PÚBLICAS COMO PESQUISA SOCIAL
}

Márcia da Silva Pereira Castro ${ }^{1}$

UERN: https://orcid.org/0000-0001-7269-1515

DOI: $10.21680 / 1982-1662.2021$ v4n31ID24466

SOUZA, Lincoln Moraes de. Aspectos teóricos da avaliação de políticas públicas. Curitiba: CRV, 2019.

O livro trata-se de uma publicação póstuma do professor Lincoln Moraes de Souza. É uma espécie de respostas a interrogações longínquas que, primeiramente, levaram o autor a compor o trabalho e defendê-lo para obtenção do título de professor titular na Universidade Federal do Rio Grande do Norte (UFRN) em 18 de agosto de 2018. Assim, transformado em livro, o texto expressa parte das reflexões que perpassaram os estudos sobre Avaliação de Políticas Públicas do autor nos últimos anos, particularmente, na condução de atividades diversificadas no âmbito da UFRN. É, portanto, uma revisão bibliográfica que foi composta ao longo de anos se debruçando nos estudos sobre Avaliação de Políticas Públicas.

Lincoln foi graduado em Ciências Sociais pela Universidade Federal do Ceará (UFC) em 1973, concluindo o Mestrado em Sociologia na Universidade de Brasília (UnB) em 1978. Foi professor efetivo da Universidade Federal do Rio Grande do Norte (UFRN) de 1992 a 2020 lotado no Departamento de Ciências Sociais e, nesse meio tempo, cursou Doutorado em Política Social pela Universidade Estadual de Campinas (UNICAMP), concluindo em 2004. Passou a compor o quadro docente do Programa de Pós-graduação em Ciências Sociais no ano de 2006 iniciando de forma mais sistemática sua jornada no campo da avaliação de políticas públicas, mas sem renunciar a outras

\footnotetext{
${ }^{1}$ E-mail: marciasilva@uern.br
} 
temáticas transversais: Estado, democracia, gestão popular, governo, como também, análise de políticas públicas.

Foram anos desenvolvendo atividades de orientação de mestrandos/as e doutorandos/as, participação em eventos e publicação de livros e artigos sobre a avaliação de políticas públicas enquanto pesquisa social, mas também ministrando cursos e disciplinas que envolviam a discussão do referido tema e outros que lhe perpassavam. Em 2009, o Grupo Interdisciplinar de Avaliação de Políticas Públicas (GIAPP/UFRN) é formalizado junto ao Conselho Nacional de Desenvolvimento Científico e Tecnológico (CNPq) como resultante dos encontros e discussões que vinham sendo realizados desde 2007, sendo o professor Lincoln seu vice-líder e o professor João Matos do Departamento de Economia (UFRN) seu líder.

Desmesuradamente adepto do rigor metodológico, na Introdução que compõe o primeiro capítulo, Lincoln justifica a opção pelo título do livro em virtude das alternativas possíveis, já que nenhuma iria dar conta da tese principal exposta no conteúdo: “a avaliação de políticas públicas, enquanto pesquisa social”. Assim, o limite temporal do trabalho teve como núcleo central para essa exposição os anos 1990 e parte do início dos anos 2000. Seguindo a rigidez do método científico, na Introdução há uma apresentação do problema de pesquisa, hipótese, justificativa (relevância teórica, social e originalidade), bem como objetivo central e específico da obra que se desenvolve nos capítulos seguintes.

No segundo capítulo intitulado A teoria no geral, as raízes e contribuições importantes sobre a avaliação de políticas públicas, o autor resgata alguns estudos da avaliação que foram realizados nas décadas de 1960, 1970 e 1980. Mesmo não se constituindo o núcleo central do livro, na releitura que foi feita como objetivo resgatar as raízes das teorias de avaliação, já que elas tiveram sua importância para as discussões que emergiram a partir da década de 1990. Se ancorando numa diversidade de autores, Lincoln nos traz uma revisão de literatura concisa, mas profundamente densa de informações, própria daqueles que levaram anos de estudos para conseguir tal façanha.

Como foi apontado na Introdução, o núcleo central do estudo (meados de 19902000), se voltaria a analisar escritos que conseguiram melhor sistematizar as tentativas de teorização da avaliação de políticas públicas. Dessa forma, as obras de, Chen (1990), Shadish Jr., Cook e Leviton (1991), e de Alkin e Christie (2004) ganham 
centralidade em partes do livro e são maiormente detalhados no capítulo seguinte. Todavia, a recorrência a autores que os antecederam e foram responsáveis para a discussão da teoria ou teorias da avaliação de políticas públicas se fez necessário, com particular destaque para Weiss $(1978 ; 1995 ; 1997 ; 1998 ; 2000)$ e Rossi, Lipsey e Freeman (2004). Na década de 1960, o destaque é para Campbell e Stanley (1979), responsáveis pela abordagem ou teoria black box, evidenciando o desenho experimental e quase-experimental. $\mathrm{Na}$ década seguinte, já se identificava os primeiros questionamentos à black box e a emergência de outras propostas e elementos teóricos. Segundo Lipsey (2011) o início dos anos 1970 marca o surgimento de um novo campo de estudos, no caso, a avaliação de programas sociais considerados como pesquisa aplicada e, por sua vez, apresentando problemas de implementação; duas publicações de 1972 demarcaram essa mudança: a de Weiss, e, Rossi e Wright, os quais exerceram, posteriormente, uma grande influência no desenvolvimento da teoria ou das teorias da avaliação. Já nos anos 1980, emerge a premissa que cada programa social incorporava uma teoria e, dentre os trabalhos publicados se emanava a necessidade de se discutir a teoria na avaliação (BICKMAN, 1987; SHADISH JR., SCHEIRER; WHOLEY, 1987). Na sequência o que se tem na década de 1990 em diante é o crescente uso da teoria do programa que, inclusive, as agências internacionais de desenvolvimento passaram a requerer projetos, programas e políticas a partir dessa concepção também denominada de modelo lógico.

No terceiro capítulo, As sínteses iniciais e classificações mais amplas de teorias da avaliação, se recorre a algumas classificações de autores considerados como centrais na discussão da teoria ou teorias da avaliação a partir dos anos 1990: Chen (1990), Shadish Jr., Cook e Leviton (1991) e de Alkin e Christie (2004). Segundo Lincoln, esses autores foram mais sistemáticos e detalhados em suas análises, por consequência, exerceram maior influência no campo em estudo. Contudo, o capítulo inicia com uma recorrência à Weiss (2000) destacando uma observação dela: "haveria duas fontes de teoria da avaliação, no caso, as crenças dos participantes do programa e a literatura de ciências sociais". Incluindo nessa interpretação, outros autores como Chen e Rossi (1983) e Green e MCAllister (1998) também apontam que ao se reportar à literatura de ciências sociais se poderia falar de grande teoria. No caso da teoria da avaliação seria algo mais restrito tipo o modelo lógico, ou, o modelo de como o programa está suposto para trabalhar; separação essa que Lincoln não concebe. 
Sharpe (2011) também apresenta concepção similar a essa interpretação Chen e Rossi (1983) e Green e MCAllister (1998).

Um apontamento interessante é adotado por Chen (1990) e outros que são retomados ao longo do livro: é a diferença estabelecida entre teoria prescritiva (conjunto de regras, prescrições e proibições) e teoria descritiva (descrevem o que de fato ocorre) da avaliação. Em seu conhecido livro, Theory-driven evaluations, Chen (1990) prefere denominar teoria normativa no lugar de teoria prescritiva, e, teoria causativa no lugar de teoria descritiva. Outra ampla classificação encontrada em Shadish Jr. (1998), bem como Christie e Alkin (2008) são as denominadas teoria geral da avaliação e teorias particulares ou específicas da avaliação. Shadish (1987) ainda traz uma contribuição importante que é a diferença ente microteoria do programa (descreve as características mais estruturais e operacionais) e macroteoria do programa (detalha os fatores econômicos, organizacionais, psicológicos e políticos) que envolvem a implementação. Já Donald e Lipsey (2006) colocam que há três tipos de teorias encontradas na avaliação: teoria da avaliação, teoria da ciência social e teoria do programa.

Após uma exposição sucinta sobre as análises de Chen (1990), na sequência do capítulo, Lincoln desenvolveu uma profunda exposição das outras duas classificações que se propôs para esse capítulo a partir de: Shadish Jr., Cook e Leviton (1991) e de Alkin e Christie (2004). O conteúdo traz uma meticulosa revisão bibliográfica sobre a produção desses autores, o que carece do leitor, à princípio, familiaridade com a literatura de avaliação de políticas públicas, já que eles retomam diversos autores (alguns já citados nos capítulos anteriores) para fazerem classificações as mais diversas. Entretanto, a forma didática como Lincoln sintetizou o texto em quadros, permite maior fluidez na compreensão do processo (de tentativa) de construção da teoria da avaliação.

Para Shadish Jr., Cook e Leviton (1991), não haveria textos que tratassem de forma abrangente e detalhada as fundamentações teóricas da avaliação, apesar de reconhecerem que nos 20 anos anteriores houve significativos avanços. Chamam a atenção para o conteúdo empírico e o destaque para o estudo de Pressman e Wildavsky (1998) onde mostram como a implementação de um programa não é feita de maneira uniforme e isso é um elemento para a prática da avaliação. Retomam autores como Scriven, Campbell, Weiss, Wholey, Stake, Cronbach, Rossi que, considerados 
autores clássicos, proporcionaram diversificadas contribuições às questões teóricas da avaliação (construção do conhecimento, uso do conhecimento, práticas de avaliação etc.). Como continuidade dessas arguições, o texto de Shadish (1998) defende algumas proposições: $1^{\text {a }}$ ) necessidade de teorias da contingência; $2^{a}$ ) carência de uma linguagem metateórica comum e estrutura para categorizar, o que requer um conjunto de termos para serem usados no debate; $3^{\mathrm{a}}$ ) necessidade de uma teoria comparativa da avaliação; $4^{\mathrm{a}}$ ) necessidade de articulação entre teoria e prática. No geral, Shadish (1998) enfatiza que a teoria da avaliação é "quem nós somos" (linguagem, coisas do campo, temas, identidade, face e conhecimento básico), já que são conhecimentos básicos que o avaliador deve possuir.

Para Alkin e Christie (2004), o intitulado Evaluation theory tree, é uma árvore composta com diferentes ramos ligados a uso, métodos e valoração. É composto por uma classificação de teorias da avaliação onde quase todas são prescritivas por oferecerem um conjunto de regras, proibições e prescrições. Trata-se de um estudo mais amplo que os anteriores, envolvendo mais autores analisados do que Shadish Jr., Cook e Leviton (1991), e envolve a questão (ou ramos) de métodos, valores/valorizações e uso, relacionando-os diretamente com teorias gerais da avaliação. Alkin e Christie também se utilizaram de parâmetros amplos como accountability ou responsabilização e a investigação social sistemática. Para eles, o principal ramo é o do método que equivale ao que Shadish Jr., Cook e Leviton (1991) denominaram de construção do conhecimento e nele são citados autores como Tyler, Campbell, Cook, Boruch, Suchman, Rossi, Weis, Chen e Cronbach. No ramo valoração se recorre a Scriven, Einer, Stake, Wolf/Owens, House, MacDonald e Guba \& Lincoln. Já no ramo uso (orientação da avaliação para o processo de tomada de decisão), os autores destacados foram: Stufflebeam, Provus, Wholey, Patton, Alkin, Fetterman, King, Cousins, Owen e Preskill. Um dado que Lincoln chama a atenção é que há uma subestimação por parte de Alkin e Christie (2004) da grande contribuição que Weiss desempenhou nas propostas de teoria ou teorias da avaliação de políticas públicas e, como veremos, no capítulo seguinte Weiss ganha destaque e se sobressai na classificação do que Lincoln chama de grandes abordagens.

O quarto capítulo, nominado de Grandes abordagens e propostas de teorias nucleares de avaliação, nos brinda com a sistematização de três grandes propostas teóricas de avaliação: black box, teorias da mudança e theory-driven e seus 
respectivos autores, Campbell, Weiss e Rossi e Chen. É consenso entre vários autores que apesar das ambiguidades de termos presentes na proposta de Weiss, ela é apontada como propositora da inserção de questões teóricas na avaliação com o seu texto de 1972, mas os trabalhos de Chen (1990) e de Shadish Jr., Cook e Leviton (1991) são considerados os divisores na temática.

$\mathrm{Na}$ teoria ou abordagem denominada black box tem como principal representante o Campbell e, mais particularmente, seu trabalho publicado com Stanley em 1963. É consenso entre vários autores que a black box é direcionada para a prática de entender o programa em termos de efeitos; eles destacam a importância de se avaliar os desenhos experimentais e quase-experimentais, a validade interna e externa e a randomização como parte da proposta. Em outro trabalho de 1979, Campbell e Stanley chamam a atenção para a necessidade de avaliar os desenhos quase-experimentais, no sentido de conhecer as fontes de invalidade. Apesar das diferentes críticas e dos contratempos com a randomização, é percebível como Campbell e a black box levantaram questões relevantes em termos do método, chegando a ser considerado, por alguns, como um clássico da teoria da avaliação.

Quanto a Weiss e suas teorias da mudança, Lincoln aponta que a autora não deixa bem explícito o que denomina como teoria do programa e avaliação baseada na teoria. Apesar de ter chamado a atenção para a teoria de avaliação de políticas públicas em seu livro de 1972, foi a partir de 1995 que sua contribuição para o tema em questão teve maior repercussão, sendo considerada por Shadish Jr., Cook e Leviton (1991) um dos nomes mais representativos da segunda fase da avaliação. A autora tece uma crítica sobre o uso instrumental da avaliação; ao questionar os métodos experimentais que eram designados para obter resultados, Weiss passou a considerar a utilização dos métodos qualitativos. Comparada a outros autores, ela estaria mais relacionada à teoria descritiva, valendo ressaltar que nesses questionamentos emerge a problematização da implementação. Em sua obra de 1995, Weiss discorre sobre problemas que podem ocorrer na implementação da avaliação; já na de 1997, ela elenca vários problemas que estão relacionados à avaliação baseada na teoria, mas também leva em consideração algumas vantagens para diferentes profissões, além dos avaliadores, dentre eles, os gestores de programas e policymakers. Na publicação de 1998, ela amplia colocações da produção anterior e dentre outras questões reafirma a compatibilidade entre avaliação qualitativa e a teoria do programa. Na sua publicação 
subsequente, Weiss afirma que existem duas fontes principais de teorias: a literatura das ciências sociais e as crenças dos participantes do programa. Por fim, Weiss em sua última publicação (2003-2004) chama a atenção para o crescente uso da avaliação em vários níveis de gestão (local, nacional e internacional), assim como por fundações e agências governamentais.

Quando Lincoln se refere à Rossi, Chen e a theory-driven evaluation (avaliação baseada na teoria), ele discorre sua análise dessa abordagem ou proposta se ancorando em três obras: o livro de Shadish Jr., Cook e Leviton (1991), o de Rossi, Lipsey e Freeman (2004) e o de Chen (1990), sendo esse último considerado o diferenciador na proposta da teoria e o demarcador de outras abordagens ou teorias. Segundo Shadish Jr., Cook e Leviton (1991), Rossi procurou introduzir uma teoria mais substantiva nas avaliações (como os programas trabalham, sobre a natureza e a causa dos problemas sociais). Já nos anos 1980, Rossi e Chen em trabalhos de coautorias, criticaram a black box por não possuir teoria e propunham a utilização da teoria da ciência social, todavia, as críticas não os colocam totalmente contrários ao paradigma experimental dominante à época, no caso, a black box; consideram que os desenhos experimental e quase experimental devem ser utilizados concomitantemente a um conhecimento prévio e teórico. Rossi, em coautoria com Lipsey e Freeman (2004), ressaltam que a teoria do programa tem sido referenciada por vários nomes (modelo lógico, teoria da ação, modelo de programa, linha de resultado, mapa de causas) e se constitui em um aspecto do programa que pode ser avaliado; ademais, eles propõem três elementos interrelacionados: teoria do impacto do programa, plano de utilização dos serviços e plano organizacional dos programas (ou teoria do processo). Contudo, Lincoln aponta o trabalho de Chen (1990), como principal referência da theory-driven evaluation e nessa obra ele chama a atenção para a importância da teoria de um programa e que ela pode revelar, dentre outras coisas, se a falha do programa está na implementação ou na teoria, seus efeitos positivos e negativos e correções necessárias. No que se refere à teoria do programa, como já foi apontado no terceiro capítulo, Chen (1990) a compreende subdividida em teoria prescritiva (normativa) e descritiva (causativa), sendo que elas se influenciam mutuamente e, ainda, com uma ressalva: as teorias normativas estariam mais articuladas ao ambiente da implementação e as teorias causativas articuladas à avaliação de impacto. Em que pese algumas particularidades entre esses autores, é perceptível que a theory-driven 
evaluation é mais conhecida pela sua contraposição à black box.

o livro por si só, poderia ter sido concluído com o exposto até o quarto capítulo, já que seu objetivo central era rastrear as teorias de avaliação, procurando seus fundamentos e transformações até o início dos anos 2000. Entretanto, o quinto capítulo é que se apresenta como conclusivo. Nele, Lincoln aponta a emersão de uma nova abordagem: a avaliação realista (PAWSON; TILLEY, 2004); nela se percebe a retomada de alguns elementos das matrizes clássicas já trabalhadas no livro; mas é uma proposta que surge para se configurar, futuramente, em uma abordagem mais concisa. Nessa perspectiva, Lincoln aponta proposições que possam potencializar teorias/propostas/abordagens mais consensuais e abrangentes, isso, se apropriando de algumas "lições" empreendidas pelos clássicos, mas também por autores contemporâneos como Pawson e Tilley (2004) e Leeuw e Donaldson (2015). São elas: desenvolver as teorias de avaliação num contexto mais amplo; vincular mais claramente a avaliação com as teorias das ciências sociais; relacionar as teorias da avaliação com teorias correlatas; e, explicitar o sentido epistemológico de conceitos e teorias de avaliação de políticas públicas.

Pelo exposto, percebe-se que a revisão bibliográfica se detém, na maior parte, em produções norte-americanas, visto que, as referências de outras nacionalidades sobre a temática são escassas. Isso não implica em afirmar que produções sobre o tema ou correlatas a ele são insignificantes como a dos franceses Mény eThoenig.

Em síntese, a obra é uma condensação de parte dos estudos sobre avaliação de políticas públicas realizados pelo professor Lincoln Moraes de Souza e que foram antecedidos por outras discussões/publicações e, com frequência, discutidos com os membros do GIAPP. Definitivamente, passa a se constituir em uma referência brasileira significativa, quiçá obrigatória, aos estudiosos de avaliação de políticas públicas. 